\title{
EFFICACY OF ARTICAINE VERSUS LIDOCAINE, AS A BUCCAL INFILTRATION COMBINED WITH INTRALIGAMENTARY INJECTION, IN MANDIBULAR MOLARS WITH IRREVERSIBLE PULPITIS- A CLINICAL TRIAL STUDY
}

\author{
Prakash Lokhande ${ }^{1}$, Vasundhara Shivanna², Deepthi Manne ${ }^{3}$, Vidhi $S^{4}$
}

${ }^{1}$ Reader, Department of Conservative Dentistry and Endodontics, College of Dental Sciences, Davangere, Karnataka, India. 2 Professor and HOD, Department of Conservative Dentistry and Endodontics, College of Dental Sciences, Davangere, Karnataka, India. 3Postgraduate Student, Department of Conservative Dentistry and Endodontics, College of Dental Sciences, Davangere, Karnataka, India.

${ }_{4}^{4}$ Postgraduate Student, Department of Conservative Dentistry and Endodontics, College of Dental Sciences, Davangere, Karnataka, India.

\begin{tabular}{l}
\hline ABSTRACT \\
\hline BACKGROUND \\
Pain should be controlled before dental procedure, which is an essential step in reducing anxiety and fear. Local anaesthesia plays \\
an important role in pain control before any endodontic treatment. Most common technique used to anaesthetize mandibular \\
molar teeth during endodontic procedure is inferior alveolar nerve block (IANB) technique with $2 \%$ lidocaine. ${ }^{1}$
\end{tabular}

\section{METHODS}

60 patients diagnosed with irreversible pulpitis of mandibular molar were selected, and were given buccal infiltration combined with intraligamentary injection by either $4 \%$ articaine (1:100000 epinephrine) or $2 \%$ lidocaine (1:80000 epinephrine) with 30 patients in each group. Endodontic access will be initiated 5 mintues after the deposition of infiltration and intraligamentary injection technique. Success will be defined as no pain or no more than mild pain before treatment, during endodontic access and instrumentation which will be measured on visual analogue scale. The Mann Whitney test was used to compare anaesthesia success between the groups.

\section{RESULTS}

The success rate after administration of $4 \%$ articaine as infiltration and intraligamentary was high (83.3\%) as compared to that of $2 \%$ lidocaine $(10.0 \%)(\mathrm{p}<0.001)$.

\section{CONCLUSIONS}

Buccal infiltration along with supplemental injection (intraligamentary) increased anaesthetic success rates for $4 \%$ articaine. Therefore, a combination of techniques should be considered prior to the root canal treatment of symptomatic irreversible pulpitis in mandibular molars.

HOW TO CITE THIS ARTICLE: Lokhande P, Shivanna V, Manne D, et al. Efficacy of articaine versus lidocaine, as a buccal infiltration combined with intraligamentary injection, in mandibular molars with irreversible pulpitis- a clinical trial study. J. Evolution Med. Dent. Sci. 2019;8(15):1216-1218, DOI: 10.14260/jemds/2019/269

\section{BACKGROUND}

Pain should be controlled before dental procedure, which is an essential step in reducing anxiety and fear. Local anaesthesia plays an important role in pain control before any endodontic treatment. Most common technique used to anaesthetize mandibular molar teeth during endodontic procedure is inferior alveolar nerve block (IANB) technique with $2 \%$ lidocaine. ${ }^{1}$

Although IANB technique is most widely used for mandibular molars before endodontic treatment, it has higher failure rate and success rate are even lower when treating the mandibular posterior teeth with irreversible pulpitis. $^{2}$

There is hyperalgesia and allodynia due to inflammatory process involved in irreversible pulpitis, which hampers profound local anaesthesia. ${ }^{3}$

'Financial or Other Competing Interest': None.

Submission 23-11-2018, Peer Review 29-03-2019,

Acceptance 05-04-2019, Published 15-04-2019.

Corresponding Author:

Dr. Prakash Lokhande,

D. No. 2651, MCC 'B' Blcok,

Davangere-577004, Karnataka, India

E-mail: prakashee19@gmail.com

DOI: $10.14260 /$ jemds $/ 2019 / 269$

\section{(c) $(1)$}

The other alternative for lidocaine is articaine which has enhanced efficacy and safety. It consists of ester group along with thiophene ring. Due to presence of thiophene ring instead of benzene ring there is increased diffusion of the articaine solution. There is increased lipid solubility which allows the solution to cross lipid membrane. ${ }^{1}$ Articaine has been shown to be a significantly better anaesthetic agent as compared to lidocaine for infiltrations. ${ }^{4}$

Generally, we give infiltration technique for maxillary teeth and block technique for mandibular teeth before carrying out the endodontic treatment to control the pain Lidocaine $2 \%$ as a buccal infiltration showed lower success as compared to that of articaine. ${ }^{5}$

Intraligamentary injections are one of the supplemental injections which raise the success rate to a reliable extent. Thus, the purpose of this study was to compare the anaesthetic success rate of buccal infiltration combined with intraligamentary injections of $4 \%$ articaine and $2 \%$ lidocaine in mandibular molars with irreversible pulpitis.

\section{METHODS}

Seventy patients who had pain in their mandibular molar who visited the college were selected for the study on single blinded randomized clinical trial. Ten patient who had swelling, younger than 18 years, changes in periapical 
radiolucency, retreatment and patient with reversible pulpitis were excluded from the study. After exclusion sixty patient who had pain in mandibular molar diagnosed with irreversible pulpitis were taken for the study. Sample size was taken based on the convenience of the study and they were then divided into two groups with thirty each.

\section{Group 1}

30 patients received $1.8 \mathrm{ml}$ buccal infiltration combined with $0.2 \mathrm{ml}$ intraligamentary injection of $4 \%$ articaine $(1: 100000$ adrenaline).

\section{Group 2}

30 patients received $1.8 \mathrm{ml}$ buccal infiltration combined with $0.2 \mathrm{ml}$ intraligamentary injection of $2 \%$ lidocaine (1:80000 adrenaline).

Buccal infiltration was given adjacent to the molar, $2 \mathrm{~mm}$ into the mucobuccal fold and at an angle of 45 degree to outer cortical plate with 30-gauge needle, till it touches bone. For intraligamentary - needle 30 gauge was inserted into the gingival sulcus along the long axis of the tooth to be treated on the mesiobuccal, distobuccal, mesiolingual and distolingual site. Endodontic access was initiated 5 minutes after the deposition of infiltration solution. Success was defined as no pain or no more than mild pain during endodontic access and instrumentation which was measured on visual analogue scale. Patients who had pain even after buccal infiltration and intraligamentary were given inferior alveolar nerve block (IANB) with lidocaine.

\section{Statistical Analysis}

All the values obtained were tabulated and subjected to statistical analysis. The Mann Whitney test was used to compare anaesthesia success between the groups. The level for significance of differences was taken as $\mathrm{p}<0.05$. $\mathrm{Z}$ test was used to compare the success rate between two groups. Success rate in group $1(83.3 \%)$ was significantly higher compared to group $2(10 \%) \mathrm{p}<0.001 \mathrm{HS}$

\section{RESULTS}

Mann-Whitney Test conducted between group 1 and group 2 exhibited statistically significant difference between two groups $(\mathrm{U}=120 ; \mathrm{p}=0.001)$ in favour of group 1 (Mean rank = 41.50 ) compared to group 2 (Mean rank $=19.50$ ) with more number of successful variables (Table 1 ).

$\mathrm{Z}$ test was used to compare the success rate between two groups. Success rate in group $1(83.3 \%)$ was significantly higher compared to group $2(10 \%) \mathrm{p}<0.001$ HS. (Table 1 and 2)

\begin{tabular}{|l|c|c|c|c|c|}
\hline Groups & $\mathbf{N}$ & Unsuccessful & Successful & $\begin{array}{c}\text { Mean } \\
\text { Rank }\end{array}$ & p Value \\
\hline Group 1 & 30 & 5 & 25 & 41.50 & \multirow{2}{*}{ 0.001* } \\
\hline Group 2 & 30 & 27 & 3 & 19.50 & \\
\cline { 1 - 5 } Table 1. & & &
\end{tabular}

Table 1. Mann-Whitney Test Between Group 1 and Group 2 *Statistical significance set at 0.05

\begin{tabular}{|c|c|c|c|}
\hline \multirow{2}{*}{ Groups } & \multirow{2}{*}{ Success Rate } & Group 1 vs. Group 2 \\
\cline { 2 - 3 } & & Z Value & Significance \\
\hline Group 1 & $83.3 \%$ & \multirow{2}{*}{8.39} & $\mathrm{p}<0.001$ HS \\
\hline Group 2 & $10.0 \%$ & & \\
\hline \multicolumn{3}{|c|}{ Table 2. Z Test to Compare the Success Rate Between the } \\
Two Groups \\
\hline
\end{tabular}

\section{DISCUSSION}

Pain assessment is difficult to access, because of its intensity and perception. Standardizing and quantifying pain objectively among the group of individuals is challenging. Traditionally, numeric and verbal self-rating scales or behavioural scales have been used in clinical research. As per the clinical research, visual analogue scale (VAS) was found to be methodologically sound, easy to administer and simple. With limited drawbacks like understanding and perception, VAS provides validated and meaningful measure of anaesthetic efficacy. ${ }^{6}$

Local anaesthesia is best and safe method to achieve painfree endodontic treatment for the patients. However, there is $23 \%$ failure rate with IANB technique when used for mandibular molar anaesthesia.7,8 The failure of IANB technique may be due to: poor operator technique, anatomic (Position of foramina, accessory innervations, accuracy of injection) and improperly stored cartridges. ${ }^{9}$ With addition to limited efficacy it has few possible disadvantages like intravascular damage and nerve damage..$^{10}$

Therefore, we need to find other alternative technique to IANB to increase the success rate in mandibular anaesthesia. Buccal infiltration is easy to perform, anaesthetizes any accessory innervations and simple technique. But this technique is usually not preferred in mandibular molars due to presence of thick cortical plate which do not allow proper diffusion of solution into bone.11 Recently, Kanaa et al stated that $4 \%$ articaine with $1: 100000$ epinephrine is more effective in mandibular molars with buccal infiltration, due to presence of thiophene ring which allows to diffuse more readily. ${ }^{12}$

Supplemental anaesthesia should be considered when success rate of any technique/solution is lower. The alternative technique can be implemented to avoid regional block technique, like buccal infiltration followed by intraligamentary with articaine. This method is more comfortable to operator and patient, easier to perform, avoid possible damage to nerve and without numbness of lip. ${ }^{2}$

Articaine with $4 \%$ concentration has equal efficacy when compared to $2 \%$ lidocaine. It has lower systemic toxicity and increased diffusion into bone and hence it is possible to inject lesser volume, thereby minimizing pain due to injection. ${ }^{13}$

The major metabolic product of articaine is articainic acid which is inactive and has no systemic toxicity as compared to xylidide which is active metabolite of lidocaine. Thus, to decrease systemic toxicity $2 \%$ lidocaine is used for local anaesthesia. ${ }^{13}$

In the present study, $4 \%$ articaine showed better results as compared to that of $2 \%$ lidocaine due to following reason: increased lipid solubility, thiophene ring, increased protein binding which increases duration of action. ${ }^{14}$

\section{CONCLUSIONS}

Articaine has become popular over the gold standard lidocaine due its excellent efficacy. Inferior alveolar nerve block which was seldom missed by dentists can be replaced by buccal infiltration with articaine which showed good results because of it bone penetration properties.

Buccal infiltration with $4 \%$ articaine along with supplemental injection (intraligamentary) increased anaesthetic success rates, and therefore, a combination of 
techniques should be considered prior to the root canal treatment of symptomatic irreversible pulpitis in mandibular molars.

\section{REFERENCES}

[1] Arali V, Mytri P. Anaesthetic efficacy of $4 \%$ articaine mandibular buccal infiltration compared to $2 \%$ lignocaine inferior alveolar nerve block in children with irreversible pulpitis. J Clin Diagn Res 2015;9(4):ZC65-7.

[2] Monteiro M R, Groppo FC, Haiter-Neto F, et al. 4\% Articaine buccal infiltration versus $2 \%$ lidocaine inferior alveolar nerve block for emergency root canal treatment in mandibular molars with irreversible pulpitis: a randomized clinical study. Int End J 2015;48(2):145-52.

[3] Allegretti C, Sampaio R, Horliana AC, et al. Anesthetic efficacy in irreversible pulpitis: a randomized clinical trial. Braz Dent J 2016;27(4):381-6.

[4] Sood R, Hans MK, Shetty S. Comparison of anesthetic efficacy of $4 \%$ articaine with 1:100, 000 epinephrine and $2 \%$ lidocaine with $1: 80,000$ epinephrine for inferior alveolar nerve block in patients with irreversible pulpitis. J Clin Exp Dent 2014;6(5):e520-3.

[5] Flanagan DF. The effectiveness of articaine in mandibular facial infiltrations. Local Reg Anesth 2015;9:1-6.
[6] Aitken RC. Measurement of feelings using visual analogue scales. Proc R Soc Med 1969;62(10):989-93.

[7] McLean C, Reader AI, Beck M, et al. An evaluation of $4 \%$ prilocaine and 3\% mepivacaine compared with $2 \%$ lidocaine (1:100000 epinephrine) for inferior alveolar nerve block. J Endod 1993;19(3):146-50.

[8] Mikesell P, Nusstein J, Reader A, et al. A comparison of articaine and lidocaine for inferior alvelolar nerve blocks. J Endod 2005;31(4):265-70.

[9] Meechan JG. How to overcome failed local anesthesia. Br Dent J 1999;186(1):15-20.

[10] Malamed SF. Handbook of local anesthesia. $5^{\text {th }}$ edn. St. Louis: Mosby 2004.

[11] Poorni S, Veniashok B, Senthilkumar AD, et al. Anesthetic efficacy of four percent articaine for pulpal anesthesia by using inferior alveolar nerve block and buccal infiltration techniques in patients with irreversible pulpitis: a prospective randomized double-blind clinical trial. J Endod 2011;37(12):16037.

[12] Kanaa MD, Whitworth JM, Corbett IP, et al. Articaine and lidocaine mandibular buccal infiltration anesthesia: a prospective randomized double-blind cross-over study. J Endod 2006;32(4):296-8.

[13] Ali SG, Mulay S. Articaine vs Lidocaine: a review. IOSR J Dent \& Med Sci 2014;13(9):40-4.

[14] Yapp KE, Hopcraft MS, Parashos P. Articaine: a review of the literature. Br Dent J 2011;210(7):323-9. 